\title{
Formation of 8-hydroxydeoxyguanosine by asbestos and man made mineral fibres
}

\author{
P LEANDERSON, P SÖDERKVIST, C TAGESSON, O AXELSON \\ From the Departments of Occupational Medicine and Clinical Chemistry, University Hospital, S-581 85 \\ Linköping, Sweden
}

\begin{abstract}
Samples of rockwool and glass fibre were compared with chrysotile fibres for their capacity to hydroxylate 2-deoxyguanosine to 8-hydroxydeoxyguanosine, a reaction that is mediated by formation of hydroxyl radicals. All three fibres produced 8-hydroxydeoxyguanosine in the absence of $\mathrm{H}_{2} \mathrm{O}_{2}$. The chrysotile fibres were most potent and produced about ten times more of the modified nucleoside than rockwool and glass fibre. This investigation shows that not only asbestos but also man made mineral fibres are able to modify nucleosides.
\end{abstract}

Several epidemiological and experimental studies have shown the carcinogenic properties of asbestos fibres ${ }^{1}$ but the underlying molecular mechanisms have not yet been clarified. Recent studies indicate that asbestos fibres can induce the formation of reactive oxygen metabolites and that the ensuing free radicals may damage DNA. It has therefore been suggested that surface components of chrysotile, crocidolite, and amosite may catalyse formation of hydroxyl radicals $(\mathrm{OH})$ and other reactive oxygen compounds. ${ }^{2}$ Such reactive oxygen species may cause DNA strand breaks ${ }^{4}$ and pyrimidine base modifications ${ }^{5}$ in various experimental systems and a cellular oxidative stress has therefore been proposed to play a major part in carcinogenesis. $^{6}$

Kasai and Nishimura studied the $\mathrm{OH}$-mediated hydroxylation of deoxyguanosine (dG, fig 1, left) to 8hydroxydeoxyguanosine $(8-\mathrm{OH}-\mathrm{dG}$, fig 1 , right) in a cell free system containing ascorbic acid, $\mathrm{Fe}^{2+}$, EDTA, and $\mathrm{O}_{2}{ }^{7}$ It was found that the combined action of asbestos and $\mathrm{H}_{2} \mathrm{O}_{2}$ resulted in hydroxylation of $\mathrm{dG}$ in calf thymus DNA and potentiated the hydroxylation of $\mathrm{dG}^{3}$ Such a formation of 8-OH-dG and other modified DNA bases is likely to cause structural and conformational changes in the DNA molecule and so increase the mispairing rate during DNA replication and repair. Thus it may be hypothesised that the carcinogenic effect of asbestos is due to free radical mediated DNA damage and that the carcinogenic potential of different fibres may be assessed by measuring their ability to hydroxylate dG to 8-OH-dG (fig 1).

The carcinogenic properties of asbestos have caused

Accepted 22 June 1987 restrictions in its use and efforts have been made to find substitutes, usually other fibrous materials. Fibrous materials, however, have also been used for a long time as insulation in the construction industry and the energy crisis has resulted in increasing efforts in this respect also with regard to old buildings. Therefore, many workers are exposed to man made mineral fibres (MMMF). A large cohort study of workers in different European countries has recently been carried out by the International Agency for Research on Cancer and found an excess risk of lung cancer associated with exposure to $M M M F .{ }^{8}$ Intrapleural or intraperitoneal injections of glass fibres and other MMMF in experimental animals have shown some carcinogenic effects. ${ }^{9}$ In vitro experiments with glass fibre have resulted in chromosome aberrations in culture cells ${ }^{10}$ and morphological transformation of Syrian hamster embryo cells in culture."

In this study we show that two important MMMFs, rockwool and glass fibre, both induce the formation of $8-\mathrm{OH}-\mathrm{dG}$ from $\mathrm{dG}$, although not to the same extent as asbestos.

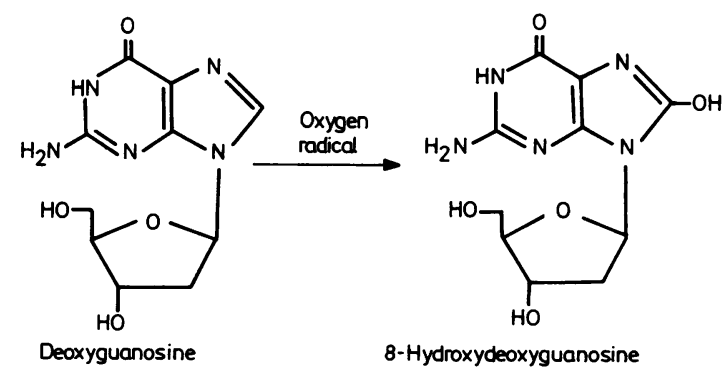

Fig 1 Formation of $8-O H-d G$ by hydroxylation of $d G$. 


\section{Materials and methods}

FIBRES AND CHEMICALS

Rockwool was provided by Dr Rockwool Inc, Skövde, Sweden, and crysotile and glass fibre by $\mathrm{Dr}$ Bengt Christensen, National Board of Occupational Safety and Health, Solna, Sweden. 2'-Deoxyguanosine (research grade) was obtained from Serva Feinbiochemica GMBH \& Co, Heidelberg FRG; 8-OH-dG was synthesised according to Kasai and Nishimura. ${ }^{7}$

\section{EXPERIMENTAL CONDITIONS}

Fibres (45 mg) were mixed with $100 \mu 110 \mathrm{mM} \mathrm{dG}$ and $2.0 \mathrm{ml} 100 \mathrm{mM}$ phosphate buffer, $\mathrm{pH} \mathrm{7.5}$. The mixtures were incubated in the dark at $37^{\circ} \mathrm{C}$ for up to 27 hours using a shaking water bath. After incubation for various periods the samples were allowed to sediment for 10 minutes and an aliquot of the supernatant was analysed for 8-OH-dG.

\section{ANALYSIS}

8-OH-dG was determined using high performance liquid chromatography. A LDC constametric III pump with an amperometric electrochemical detector (Zäta 4C, Zäta Elektronik, Lund, Sweden) was used. The detector was equipped with a LC-17 cell from Bioanalytical Systems Inc and in the oxidative mode $(0.60 \mathrm{~V})$ as decribed by Floyd et al. ${ }^{12}$ After sedimentation of the fibres, $20 \mu$ l of the reaction mixture was injected on to a Rainin microsorb C 18 column ( 3 $\mu \mathrm{m}, 150 \times 4.6 \mathrm{~mm})$. The mobile phase consisted of $10 \%$ aqueous methanol containing $12.5 \mathrm{mM}$ citric acid, $25 \mathrm{mM}$ sodium acetate, $30 \mathrm{mM} \mathrm{NaOH}$, and 10 $\mathrm{mM}$ acetic acid.

\section{Results}

Figure 2A shows the chromatographic behaviour of 8-OH-dG. Chrysotile fibres produced 8-OH-dG efficiently even in the absence of $\mathrm{H}_{2} \mathrm{O}_{2}$ (fig 2B). Rockwool and glass fibres also produced 8-OH-dG but not as efficiently as chrysotile (figs $2 \mathrm{C}$ and $2 \mathrm{D}$, respectively). Under the incubation conditions used, the fibres caused a linear increase in 8-OH-dG-content up to at least $27 \mathrm{~h}$ (fig 3 ). During 20 hours incubation of rockwool and glass fibre, about 50 and 30 pmol 8$\mathrm{OH}-\mathrm{dG}$ were produced, respectively. On the other hand, chrysotile was more efficient in generating 8$\mathrm{OH}-\mathrm{dG}$ and under corresponding incubation conditions about $500 \mathrm{pmol}$ was produced (data not shown). In the control incubation (without fibres) only trace amounts $8-\mathrm{OH}-\mathrm{dG}$ were detectable (figs $2 \mathrm{E}$ and 3 ).

\section{Discussion}

The experiments performed show that the presence of asbestos, rockwool, or glass fibres in an incubation mixture containing the nucleoside $\mathrm{dG}$ but no $\mathrm{H}_{2} \mathrm{O}_{2}$ results in a hydroxylation of dG to 8-OH-dG. Earlier, Kasai and Nishimura have shown that different types of asbestos fibres have different capacities to hydroxylate $d G$ in calf thymus DNA in the presence of $\mathrm{H}_{2} \mathrm{O}_{2}{ }^{3}$ Chrysotile, crocidolite, and amosite were then shown

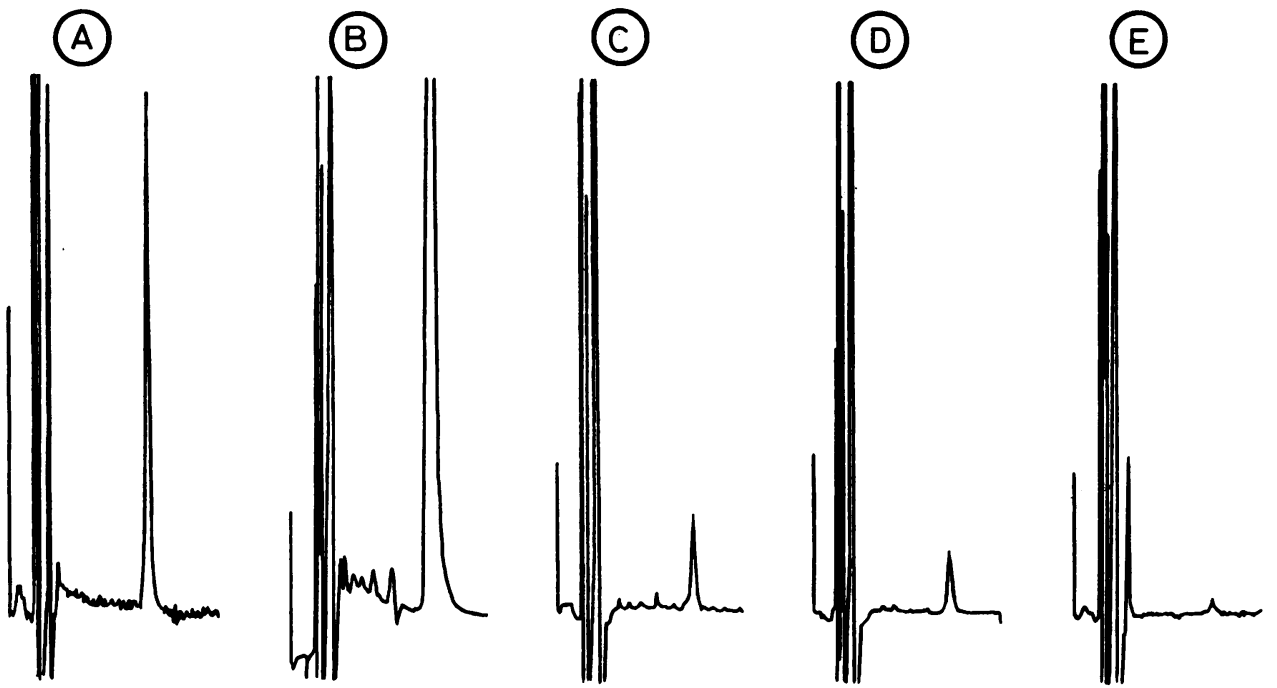

Fig 2 HPLC chromatograms showing formation of 8-OH-dG in different samples: (A) external standard, 2 pmol, (B) chrysotile sample, (C) rock wool sample, (D) glass fibre sample, $(E) d G$ without any fibre. Samples $B$-E were incubated for 20 hours. Sample volume, $20 \mu \mathrm{l}$. 


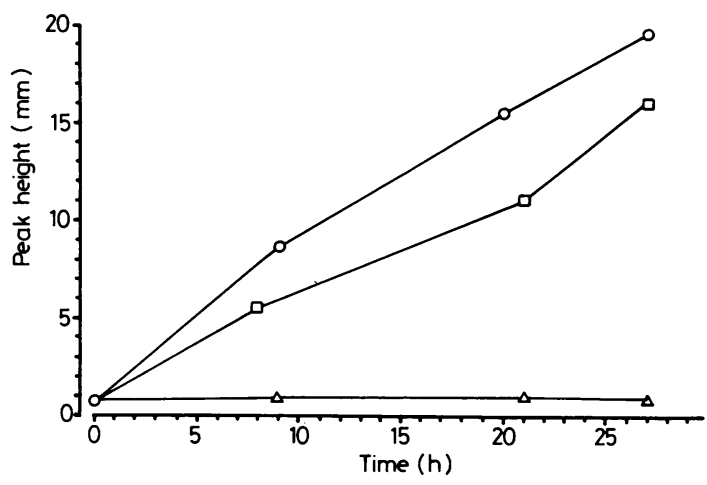

Fig 3 Formation of 8-OH-dG $\mathrm{v}$ time in mixtures containing rock wool ( $\bigcirc)$, glass fibre ( $\square)$, and without fibre $(\triangle)$.

to be more efficient than, for instance, antophyllite.

It has been suggested that the molecular mechanism for formation of 8-OH-dG involves free radicals and, in particular, hydroxyl radicals. Dizdaroglu was able to separate and identify 12 different modifed DNA bases, among them 8-OH-dG after irradiation with $x$ rays. ${ }^{13} X$ Rays are known to generate hydroxyl radicals in several biological systems and this is believed to be the molecular basis for the carcinogenic effects of radiation. ${ }^{36}$

Concerning asbestos and other mineral particulates, possibly the surface area is responsible for the generation of hydroxyl radicals. By using electron spin resonance spectroscopy Zalma et al showed that asbestos and other mineral particles produced free radicals. ${ }^{13 a}$ In line with these observations it seems plausible to expect other mineral fibre surfaces to harbour similar properties. To our knowledge this is the first time MMMFs such as rockwool and glass fibre have been shown to generate reactive oxygen intermediates that hydroxylate dG. By contrast with Kasai and Nishimura, these results were obtained without any addition of $\mathrm{H}_{2} \mathrm{O}_{2}$. Our results in this respect could be explained by the use of the HPLC-EC system which is at least a 1000 fold more sensitive than ultraviolet detection system as outlined by Floyd $e t$ $a .^{12}$

During recent years oxygen radicals have received much attention as a mechanism of action in the carcinogenic process. ${ }^{614}$ The carcinogenic action of asbestos has so far been unclear, but the surface activation of oxygen to oxygen radicals represents an attractive explanation as one important factor in this complex process. Factors such as oxygen radical formation capacity, surface area, and biological stability of the fibre may be important for the overall activity. The hydroxyl radical producing capacity may be related to the surface area of the fibre rather than weight (unpublished observations).

The quantitative differences observed between asbestos and MMMFs in our simple system seem somewhat to parallel epidemiological findings, and it is therefore tempting to speculate that generation of hydroxyl radicals could represent an important step in the carcinogenic action of asbestos, rockwool, and glass fibres.

This work was in part supported by a grant from the County Council of Östergötland Research Fund.

\section{References}

1 International Agency for Research on Cancer. Monographs on the evaluation of the carcinogenic risk of chemicals to man. Vol 14 Ashestos. Lyon: IARC, 1977:42-7.

2 Weitzman SA, Graceffa P. Asbestos catalyzes hydroxyl and superoxid radical formation from hydrogen peroxide. Arch Biochem Biophys 1984:228:373-9.

3 Kasai $\mathrm{H}$, Nishimura S. DNA damage induced by asbestos in the presence of hydrogen peroxide. GANN 1984:75:841-4.

4 Achey P. Duryea H. Production of DNA strand breaks by the hydroxyl radical. Int J Radiat Biol Relat Stud Phys; Chem Med 1974:25:595-601.

5 Cerutti PA. Photochemistry and photobiology of nucleic acids bases. In: Wang SY ed. New York: Academic Press, 1976;2: 375-426.

6 Cerutti PA. Pro-oxidant states and tumor promotion. Science 1985;227:375-80.

7 Kasai H, Nishimura S. Hydroxylation of deoxyguanosine at the C8 position by ascorbic acid and other reducing agents. Nucleic Acid Research 1984:12:2137-45.

8 Saracci R, Simonato L. Mortality and incidence of cancer of workers in the man made vitreous fibres producing industry: an international investigation at 13 European plants. $\mathrm{Br} J$ Ind $\mathrm{Med}$ 1984:41:425-36.

9 Stanton MF, Layard M. Tegeris A, et al. Carcinogenicity of fibrous glass: pleural response in the rat in relation to fiber dimension. J Natl Cancer Inst 1977;58:587-603.

10 Sincock AM, Delhanty JDA, Casey G. A comparison of the cytogenic response to asbestos and glass fibre in Chinese hamster and human cell lines. Mutat Res 1982:101:257-68.

11 Hesterberg TW, Barrett JC. Dependence of asbestos and mineral dust induced transformation of mammalian cells in culture on fibre dimensions. Cancer Res 1984;44:2170-80.

12 Floyd RA, Watson JJ, Wong PK, Altmiller DH, Rickard RC. Hydroxyl free radical adduct of deoxyguanosine: sensitive detection and mechanism of formation. Free Radical Research Communication 1986;1:163-72.

13 Dizdaroglu M. Application of capillary gas chromatography-mass spectrometry to chemical characterisation of radiation-induced base damage of DNA: implications of assessing DNA repair processes. Anal Biochem 1985:144:593-603.

13a Zalma R. Bonneau L, et al. Formation of oxy radicals by oxygen reduction arising from the surface activity of asbestos. Canadian Journal of Chemistry 1987;65:2338-41.

14 Ames BN. Dietary carcinogens and anticarcinogens. Science 1983:221:1256-64. 